\title{
Intraperitoneal chemotherapy for gastric cancer with peritoneal metastasis
}

\author{
Daisuke Kobayashi $^{1} \cdot$ Yasuhiro Kodera $^{1}$
}

Received: 30 August 2016/Accepted: 15 October 2016/Published online: 1 November 2016

(c) The International Gastric Cancer Association and The Japanese Gastric Cancer Association 2016

\begin{abstract}
Peritoneal metastasis is the most frequent pattern of gastric cancer recurrence or metastasis and is a definitive determinant of prognosis. However, an effective means of treating peritoneal disease has not yet been established. Systemic chemotherapy has only a limited effect on peritoneal metastasis, although some progress has been shown in terms of median survival time, especially among patients with a minimal or moderate disease burden. Clinical research related to intraperitoneal administration of anticancer drugs is currently underway. An advantage of intraperitoneal chemotherapy is the ability to achieve high concentrations of anticancer drugs in the peritoneal cavity and the direct exposure of peritoneal deposits and free cancer cells to those drugs. In addition, pharmacokinetic studies with taxanes have shown that these high intraperitoneal drug concentrations are sustained for a considerable length of time, allowing prolonged exposure. As taxanes are the most appropriate drugs for intraperitoneal administration, the development of repeated intraperitoneal chemotherapy using taxanes for gastric cancer peritoneal metastasis-either alone or in combination with systemic chemotherapy-has taken place over the past decade, mostly in Japan. Several phase II trials and a phase III trial have recently demonstrated the efficacy of this therapy, including median survival times of 14.4-24.6 months and one-year overall survival rates of $67-91 \%$. These results may lead to the approval of intraperitoneal taxanes,
\end{abstract}

Daisuke Kobayashi

kobadai@med.nagoya-u.ac.jp

1 Department of Gastroenterological Surgery, Nagoya University Graduate School of Medicine, 65 Tsurumai-cho, Showa-ku, Nagoya 466-8550, Japan especially paclitaxel, for official insurance coverage in the near future.

Keywords Gastric cancer · Peritoneal metastasis . Intraperitoneal chemotherapy

\section{Introduction}

Gastric cancer cells shed into the peritoneal space are believed to develop into peritoneal metastasis, which is the most frequent pattern of recurrence after surgery for curative intent. Presence of peritoneal disease at surgery is predictive of poor outcome, and radical gastrectomy should be spared only for those with obstruction or bleeding. Further progression results in the obstruction of the gastrointestinal tract, hydronephrosis, and massive ascites, any of which leads to marked deterioration of health-related quality of life. It is irrefutable that preventing peritoneal metastasis is crucial to curing gastric cancer, while efforts to control peritoneal disease once it has developed are generally considered futile. Although there have been some improvements in median survival time (MST) for advanced/metastatic gastric cancer [1-4], chemotherapeutic regimens that specifically target peritoneal metastases have not been developed (aside from a few exceptions $[5,6])$, partly because patients with peritoneal disease rarely have measurable lesions, which are required in clinical trials performed to test new drugs. In addition, the effect of systemic chemotherapy on peritoneal metastasis is limited, possibly because of the peritoneum-plasma barrier, which prevents effective drug delivery from the systemic circulation into the peritoneal cavity [7].

Recently, clinical research on the intraperitoneal administration of anticancer drugs has shown encouraging 
progression. Intraperitoneal chemotherapy is the ideal approach due to the following advantages: (1) drugs administered intraperitoneally act directly on both the free cancer cells in the peritoneal cavity and metastatic nodules on the peritoneal surface; (2) intraperitoneal chemotherapy results in a higher drug concentration in the peritoneal cavity as compared with intravenous administration [8]; and (3) some drugs are not readily absorbed into the systemic circulation, resulting in a prolonged half-life in the peritoneal cavity and reduced systemic toxicity.

In Western countries, intraperitoneal chemotherapy is often combined with cytoreductive surgery and hyperthermia, where a heated fluid containing anticancer drugs is perfused during surgery [9]. Hyperthermia intraperitoneal chemotherapy (HIPEC) has demonstrated notable efficacy for the treatment of peritoneal metastasis arising from various malignancies in the abdomen, such as ovarian cancer [10], colorectal cancer [11], pseudomyxoma peritonei [12], and mesothelioma [13], in addition to gastric cancer [14-17]. In Japan and other Asian countries, where gastric cancer is relatively common, HIPEC has been explored as a treatment option since 1988 [18-21]. Given that the MST is reported to range from 7.9 to 11.5 months in gastric cancer cases, HIPEC is currently not considered effective enough to compensate for the morbidity and replace systemic chemotherapy. HIPEC combined with cytoreductive surgery is currently a once-in-a-lifetime procedure to be performed at the time of surgery, unlike intraperitoneal chemotherapy, which can be given repeatedly.

Repeated intraperitoneal chemotherapy is another option. Once the intraperitoneal catheter and access port are embedded in a patient, repeated administration of anticancer drugs into the abdomen without hyperthermia is easily performed and is sustainable until disease progression. A randomized phase III trial was performed for ovarian cancer, which often involves peritoneal metastasis, and the results clearly demonstrated that the regimen containing intraperitoneal chemotherapy was superior to the standard intravenous administration protocol in primary chemotherapy management of peritoneal metastasis with no residual mass $>1.0 \mathrm{~cm}$ [22]. Based on this result, the National Comprehensive Cancer Network guidelines now recommend intraperitoneal chemotherapy for patients with stage III epithelial ovarian cancer after optimal cytoreductive surgery [23]. Although intraperitoneal chemotherapy against peritoneal metastasis of gastric cancer has been reported (mainly from Japan) to be efficacious, there is little robust evidence, and intraperitoneal administration of anticancer drugs other than mitomycin C (MMC) and cyclophosphamide- which is now only rarely used to treat gastric cancer-is not officially covered by the national public health insurance in Japan. However, several clinical trials that aim to validate intraperitoneal chemotherapy have recently been conducted under the auspices of the advanced medical evaluation system organized by the Japanese Ministry of Health, Labor and Welfare.

The current review summarizes the rationale and methodology for adopting intraperitoneal chemotherapy, and some results of trials exploring intraperitoneal chemotherapy in gastric cancer patients with peritoneal metastasis. Note that we use the acronym "HIPEC" below to refer to intraperitoneal chemotherapy combined with hyperthermia, in order to distinguish it from intraperitoneal chemotherapy performed without heat.

\section{Rationale and methodology for intraperitoneal chemotherapy}

\section{Peritoneal implantable port}

A peritoneal implantable port system is used for intraperitoneal chemotherapy. In most cases, an intraperitoneal catheter and access port are implanted simultaneously during staging laparoscopy, which is performed to detect and clarify the distribution of peritoneal metastasis. A catheter is placed in the Douglas pouch, and a peritoneal access port is embedded into the subcutaneous space of the lower abdominal wall (Fig. 1). The anticancer drug is dissolved in $500-1000 \mathrm{ml}$ of saline and is repeatedly administered through the peritoneal port at the outpatient clinic. A peritoneal lavage cytological examination can easily be performed through the peritoneal port during the treatment period, and is considered to reflect the real-time efficacy of intraperitoneal chemotherapy. Conversion of the peritoneal cytology result from positive to negative is considered to be a useful indicator of response in patients who undergo intraperitoneal chemotherapy.

Emoto et al. reported that complications associated with the port system occurred in $20.6 \%$ of 131 patients in their study [24]. Inflow obstruction and infection were the main complications that occurred in 7.6 and $6.9 \%$ of the patients, respectively. The median period of intraperitoneal chemotherapy through the peritoneal port was 12.9 months (range 0.8-61.5 months). Although the duration of intraperitoneal chemotherapy was much longer than in the phase III trial using an intraperitoneal catheter for ovarian and primary peritoneal cancer [25], the port-related complication rate was lower.

\section{Theoretical concept of intraperitoneal chemotherapy}

The main advantage of intraperitoneal chemotherapy is that it leads to high concentrations of anticancer drugs in the peritoneal cavity, thus allowing prolonged direct exposure of free cancer cells or peritoneal deposits to those drugs. It 

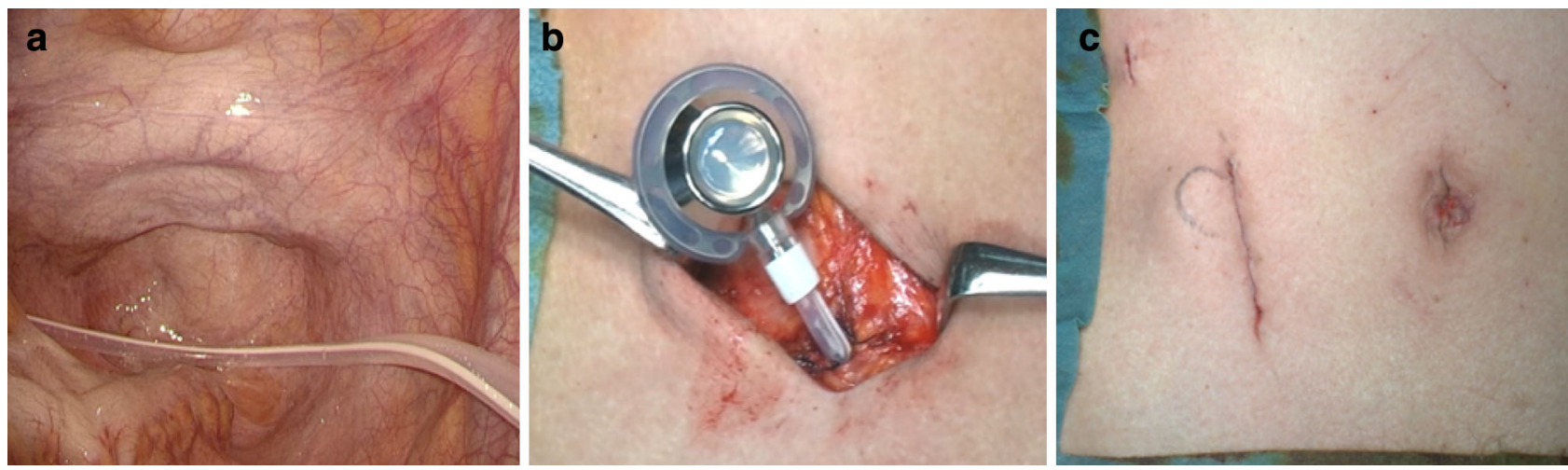

Fig. 1a-c Peritoneal implantable port system: a the catheter is placed in the Douglas pouch; $\mathbf{b}$ the peritoneal access port is embedded into the subcutaneous space of the lower abdomen; $\mathbf{c}$ the peritoneal implantable port system is used for repeated intraperitoneal chemotherapy

should also be noted that intraperitoneal chemotherapy offers an efficient and intensive regional therapy compared with conventional systemic chemotherapy. The area under the curve (AUC) ratio of the intra-abdominal space to the plasma after intraperitoneal administration is important in that it permits the dose intensity expected during the treatment of peritoneal metastasis to be calculated in relation to the toxicity observed as a result of systemic exposure to the drug.

There are, however, a few shortcomings of intraperitoneal chemotherapy. First, the depth of infiltration from the surface of the peritoneal disseminated nodules after a single intraperitoneal administration of anticancer drugs is limited [9]. Kamei et al. reported that the infiltration distance of intraperitoneally administered paclitaxel (PTX) reached approximately $100-200 \mu \mathrm{m}$ from the surface of the tumor according to fluorescence microscopy imaging [26]. Thus, multiple intraperitoneal administrations of anticancer drugs are necessary to ensure that the drugs penetrate deep into the peritoneal lining and exert their antitumor effects (just as systemic chemotherapy is usually administered repeatedly), but even then the drugs may not reach the deepest part of a large nodule. Moreover, intraperitoneal chemotherapy using a drug with favorable pharmacokinetics (slow and unsteady entry into the systemic circulation) is essentially a locoregional treatment. Only by combining it with the established systemic therapy can we expect antitumor effects to be exerted against the primary tumor or metastasis to organs other than the peritoneum, and thus a survival benefit to be achieved. Another rationale for a combination drug delivery strategy is that the tumor-bearing peritoneum can also be reached through systemic administration of the anticancer drug via subperitoneal capillaries [27]. However, a more extensive systemic chemotherapy may be given priority over intraperitoneal chemotherapy when peritoneal metastasis is accompanied by unresectable metastasis to the other organs and lymph nodes. In such cases, a standard regimen for metastatic gastric cancer such as a fluoropyrimidine/platinum combination could be combined with intraperitoneal PTX to control all types of metastases.

\section{Anticancer drugs for intraperitoneal administration}

\section{Cisplatin and mitomycin $\mathrm{C}$}

Intraperitoneal chemotherapy has been employed against early-phase peritoneal malignant tumors consisting of pseudomyxoma peritonei under hyperthermic conditions [28]. Classic anticancer drugs such as cisplatin (CDDP) and MMC were widely used in the 1990s for intraperitoneal administration, using both HIPEC and normothermic administration. One reason for selecting CDDP and MMC is the well-documented synergistic effects of these drugs with heat, as well as their thermal stabilities [9].

Intraperitoneal chemotherapy with MMC and/or CDDP has been reported to improve the survival of gastric cancer patients by preventing peritoneal recurrence in the neoadjuvant or adjuvant setting in some studies [29-36], whereas several other studies have reported a lack of efficacy of intraperitoneal chemotherapy [37, 38]. Two studies have assessed the intraperitoneal administration of MMC and/or CDDP with or without systemic chemotherapy combined with gastrectomy to treat gastric cancer with peritoneal metastasis; these yielded MSTs of 11.4 and 16.7 months, respectively $[34,39]$. Kuramoto et al. reported that extensive intraoperative peritoneal lavage by $10 \mathrm{~L}$ of physiological saline followed by intraperitoneal chemotherapy with CDDP significantly improved the 5-year survival rate of advanced gastric cancer patients with positive cytology but without macroscopic 
peritoneal metastasis; this was therefore recommended as a prophylactic strategy for peritoneal dissemination [40].

In fact, the AUC ratios of the intra-abdominal space to the plasma after intraperitoneal administration of CDDP and MMC are not very high (10-24 for MMC and 12-21 for CDDP) [41-44], indicating that when the drugs are delivered intraperitoneally they are readily absorbed through the peritoneal surface and enter the systemic circulation - they do not remain in the peritoneal cavity long enough to maintain meaningful concentrations [9]. Thus, these drugs may not be suitable for the treatment of patients with a heavy tumor burden in the peritoneal cavity. In a multicenter randomized phase III trial for serosa-positive R0 resected gastric cancer, systemic therapy with 5FU and CDDP combined with a single intraperitoneal administration of CDDP on the day of surgery failed to show a survival benefit over surgery alone [38].

\section{Taxanes}

Taxanes such as PTX and docetaxel (DTX) are considered more appropriate for intraperitoneal administration due to their pharmaceutical characteristics, and were introduced to clinical practice in the 2000 s to treat peritoneal metastasis from gastric cancer [45-47]. PTX and DTX are insoluble in water; they are solubilized with Cremophor EL (Taxol ${ }^{\circledR}$; Bristol-Myers Squibb Co.) and polysorbate 80 (Taxotere $^{\circledR}$; Aventis Pharma SA), respectively, for clinical use. Since taxanes are hydrophobic high-molecular-weight materials, intraperitoneally administered taxanes are only gradually drained from the peritoneum through lymphatic stomata that open directly into the pleural space [48, 49]. The AUC ratios of the intra-abdominal space to the plasma after intraperitoneal administration of taxanes are substantially higher (approximately 1000 for PTX, 207-552 for DTX) than those for other anticancer drugs [50, 51], and pharmacokinetic studies have robustly shown prolonged retention of PTX and DTX when they are given intraperitoneally [52, 53]. Intraperitoneal administration of taxanes has been considered a promising treatment for eliminating peritoneal metastasis of gastric cancer, as the taxanes penetrate directly into the disseminated tumors $[54,55]$.

Moreover, even when the taxanes are repeatedly administered intraperitoneally, they rarely cause fibrotic adhesions in the abdomen, in contrast to some other drugs that are known to cause local chemical peritonitis [56]. This means that surgical resection as a conversion surgery is technically feasible after intraperitoneal administration has proven exceptionally effective, and this has actually been performed aggressively with promising results.

\section{Clinical outcomes for intraperitoneal administration of PTX and DTX against peritoneal metastasis}

Recently, intraperitoneal chemotherapy using taxanes for peritoneal metastasis of gastric cancer has been developed, mainly in Japan. Clinical outcomes of intraperitoneal chemotherapy that utilize PTX and DTX for gastric cancer are shown in Tables 1 [52, 53, 57-65] and 2 [50, 66-72]. The results of ongoing or recent clinical trials performed by the Japan Intraperitoneal Chemotherapy Study Group (JIPG) to verify the efficacy of intraperitoneal chemotherapy are also shown in Table 3 [73].

After a series of phase I/phase II studies in the USA, intraperitoneal administration of PTX was verified by randomized phase III trials for use in cases of ovarian cancer (another cancer type that is commonly associated with peritoneal metastasis), and it demonstrated significant efficacy [9, 22]. Kodera et al. then conducted a phase I trial in patients with recurrent peritoneal metastasis of gastric cancer to explore the pharmacokinetics of intraperitoneal PTX [52] at a weekly dosage of $60 \mathrm{mg} / \mathrm{m}^{2}$, as established by the ovarian cancer studies. The trial confirmed that high intraperitoneal concentrations were maintained, while the disappearance of malignant ascites was observed. Ishigami et al. combined intraperitoneal administration of PTX with $\mathrm{S}-1$, an oral fluoropyrimidine that consists of tegafur, gimeracil, and oteracil in the molar ratio 1:0.4:1, and intravenous PTX as a systemic treatment component. The optimal dose of intraperitoneal PTX delivered on days 1 and 8 of a 21-day cycle along with the established combination of intravenous PTX $\left(50 \mathrm{mg} / \mathrm{m}^{2}\right.$ on days 1 and 8$)$ and oral S-1 $\left(40 \mathrm{mg} / \mathrm{m}^{2}\right.$ twice daily on days $\left.1-14\right)$ was found to be $20 \mathrm{mg} / \mathrm{m}^{2}$ in a phase I trial [53]. Subsequently, two phase II clinical studies to evaluate the efficacy and tolerability of the regimen were carried out. The first study, which targeted patients with macroscopic peritoneal metastasis and/or free cancer cells confirmed by peritoneal lavage cytology, successfully demonstrated favorable therapeutic effects: the 1-year overall survival (OS) was $78 \%$, the MST was 22.5 months, and malignant ascites disappeared or decreased in $62 \%$ of the patients. The treatment was safe and manageable, the most frequent grade $3 / 4$ adverse effects being neutropenia (38\%), leukopenia (18\%), and anemia (10\%) [59]. The second phase II trial, which only targeted patients with macroscopic peritoneal metastasis, reproduced the favorable results seen in the previous study, with a 1-year OS of $77 \%$, an MST of 17.6 months, and a similar safety profile [64].

Microscopic peritoneal metastasis diagnosed by peritoneal lavage cytology is consistently accompanied by serosa-infiltrating gastric cancer and is widely 
Table 1 Clinical outcomes of intraperitoneal chemotherapy with paclitaxel for gastric cancer

\begin{tabular}{|c|c|c|c|c|c|c|c|c|c|c|}
\hline Author, year & $N$ & $\begin{array}{l}\text { Objective* } \\
\text { setting }\end{array}$ & $\begin{array}{l}\text { IP administration } \\
\text { with PTX }\end{array}$ & $\begin{array}{l}\text { Systemic } \\
\text { therapy }\end{array}$ & $\begin{array}{l}\text { MST } \\
\text { (months) }\end{array}$ & $\begin{array}{l}1-\text { year } \\
\text { OS } \\
(\%)\end{array}$ & $\begin{array}{l}\text { 2-year } \\
\text { OS } \\
(\%)\end{array}$ & $\begin{array}{l}\text { 3-year } \\
\text { OS } \\
(\%)\end{array}$ & $\begin{array}{l}5 \text {-year } \\
\text { OS } \\
(\%)\end{array}$ & Efficacy \\
\hline $\begin{array}{l}\text { Kitayama, } 2014 \\
\text { [57] }\end{array}$ & 17 & $\begin{array}{l}\text { Advanced } \\
\text { Adjuvant }\end{array}$ & $\begin{array}{l}20-60 \mathrm{mg} / \mathrm{m}^{2} \\
6-36 \text { months }\end{array}$ & $\begin{array}{l}\text { S-1 } \\
\text { PTX }\end{array}$ & & & & & 88.2 & \\
\hline Peng, 2015 [58] & 37 & $\begin{array}{l}\text { T4a } \\
\text { Neoadjuvant } \\
\text { Phase II }\end{array}$ & $\begin{array}{l}80 \mathrm{mg} / \mathrm{m}^{2} \\
(\text { single })\end{array}$ & $\begin{array}{l}\text { S-1 } \\
\text { PTX }\end{array}$ & & & & 78 & 74.9 & \\
\hline $\begin{array}{l}\text { Imano, } 2011 \\
{[59]}\end{array}$ & 10 & P0CY1 & $\begin{array}{l}80 \mathrm{mg} / \mathrm{m}^{2} \\
\text { (single) }\end{array}$ & $\begin{array}{r}\text { S-1 or } \\
\text { PTX }\end{array}$ & 37.8 & & 70 & 56 & & \\
\hline $\begin{array}{l}\text { Imano, } 2012 \\
{[60]}\end{array}$ & 35 & $\begin{array}{l}\text { P1 } \\
\text { Phase II }\end{array}$ & $\begin{array}{l}80 \mathrm{mg} / \mathrm{m}^{2} \\
(\text { single })\end{array}$ & $\begin{array}{l}\text { S-1 } \\
\text { PTX }\end{array}$ & 21.3 & 68.6 & & & & \\
\hline $\begin{array}{l}\text { Imano, } 2012 \\
{[61]}\end{array}$ & 21 & $\begin{array}{l}\text { P1/CY1 } \\
\text { Postgastrectomy }\end{array}$ & $\begin{array}{l}80 \mathrm{mg} / \mathrm{m}^{2} \\
(\text { single })\end{array}$ & S-1 & 24 & 90.5 & & 29.8 & & \\
\hline $\begin{array}{l}\text { Kodera, } 2007 \\
{[52]}\end{array}$ & 4 & $\begin{array}{l}\text { P1 } \\
\text { Phase I }\end{array}$ & $60 \mathrm{mg} / \mathrm{m}^{2}$ & - & - & & & & & $\begin{array}{l}\text { Ascites was } \\
\text { diminished in } 2 \text { of } \\
3 \text { patients }\end{array}$ \\
\hline $\begin{array}{l}\text { Ishigami, } 2009 \\
\text { [53] }\end{array}$ & 9 & $\begin{array}{l}\text { P1 } \\
\text { Phase I }\end{array}$ & $20,30 \mathrm{mg} / \mathrm{m}^{2}$ & $\begin{array}{l}\text { S-1 } \\
\text { PTX }\end{array}$ & - & & & & & $\begin{array}{l}\text { Positive cytology } \\
\text { changed to } \\
\text { negative in } 86 \%\end{array}$ \\
\hline $\begin{array}{l}\text { Ishigami, } 2010 \\
\text { [62] }\end{array}$ & 40 & $\begin{array}{l}\text { P1/CY1 } \\
\text { Phase II }\end{array}$ & $20 \mathrm{mg} / \mathrm{m}^{2}$ & $\begin{array}{l}\text { S-1 } \\
\text { PTX }\end{array}$ & 22.5 & 78 & 46 & & & \\
\hline $\begin{array}{l}\text { Kurita, } 2011 \\
\text { [63] }\end{array}$ & 18 & $\begin{array}{l}\text { P1 } \\
\text { Phase I }\end{array}$ & $\begin{array}{c}40,60,80,90 \\
100 \mathrm{mg} / \mathrm{m}^{2}\end{array}$ & S-1 & 11 & & & & & \\
\hline $\begin{array}{l}\text { Yamaguchi, } \\
2013 \text { [64] }\end{array}$ & 35 & $\begin{array}{l}\text { P1 } \\
\text { Phase II }\end{array}$ & $20 \mathrm{mg} / \mathrm{m}^{2}$ & $\begin{array}{l}\text { S-1 } \\
\text { PTX }\end{array}$ & 17.6 & 77.1 & 44.8 & & & \\
\hline $\begin{array}{l}\text { Kodera, } 2016 \\
\text { [65] }\end{array}$ & 39 & $\begin{array}{l}\text { Adjuvant/P1/ } \\
\text { CY1 } \\
\text { Postgastrectomy } \\
\text { Phase II }\end{array}$ & $\begin{array}{l}60 \mathrm{mg} / \mathrm{m}^{2} \\
7 \text { times }\end{array}$ & $\begin{array}{l}\text { S-1 } \\
(+\mathrm{CDDP})\end{array}$ & - & & & & & $\begin{array}{l}\text { Postoperative IP } \\
\text { administration of } \\
\text { PTX was feasible }\end{array}$ \\
\hline
\end{tabular}

* T4a denotes serosa-invading gastric cancer, $P 0$ no macroscopic peritoneal metastasis, $P 1$ macroscopic peritoneal metastasis, and $C Y 1$ positive peritoneal lavage cytology

$I P$ intraperitoneal, $P T X$ paclitaxel, $M S T$ median survival time, $O S$ overall survival, $C D D P$ cisplatin

acknowledged to be an initial phase in the formation of peritoneal metastases. Intraperitoneal chemotherapy is expected to be an effective modality for curing gastric cancer at that stage. Imano et al. reported that free intraperitoneal cancer cells were eliminated by intraperitoneal PTX administration for $24 \mathrm{~h}$ after gastrectomy for gastric cancer with positive lavage cytology as the single noncurative factor [59]. Subsequently, Ishigami et al. conducted a multicenter phase II trial, the so-called CYPHOENIX trial, to explore the efficacy of S-1 in combination with intravenous and intraperitoneal PTX in 38 gastric cancer patients with positive cytology as the single noncurative factor and without macroscopic peritoneal metastasis.

From the viewpoint of the treatment strategy for intraperitoneal micrometastasis, neoadjuvant and/or adjuvant intraperitoneal chemotherapy could be effective for serosa-invading advanced gastric cancer even if peritoneal lavage cytology is negative, given that the sensitivity of peritoneal lavage cytology by conventional Papanicolaou staining is not particularly high. Kitayama et al. reported the efficacy of adjuvant intraperitoneal chemotherapy combined with systemic chemotherapy, noting a 5-year OS rate of $88.2 \%$ [57]. Peng et al. reported a 5-year OS rate of $74.9 \%$ upon administering neoadjuvant intraperitoneal chemotherapy combined with systemic chemotherapy [58]. Subsequently, a multicenter phase II trial (the GAPS study, UMIN000013109) was conducted to explore the efficacy of S-1 in combination with intravenous and intraperitoneal PTX in both the neoadjuvant and the adjuvant setting in 50 gastric cancer patients with serosa-invading gastric cancer but without peritoneal metastasis.

To date, there have been two randomized studies that have compared intraperitoneal administration of PTX to 
Table 2 Clinical outcomes of intraperitoneal chemotherapy with docetaxel for gastric cancer

\begin{tabular}{|c|c|c|c|c|c|c|c|c|}
\hline Author, year & $N$ & $\begin{array}{l}\text { Objective* } \\
\text { setting }\end{array}$ & IP administration & $\begin{array}{l}\text { Systemic } \\
\text { therapy }\end{array}$ & $\begin{array}{l}\text { MST } \\
\text { (months) }\end{array}$ & $\begin{array}{l}1 \text {-year } \\
\text { OS } \\
(\%)\end{array}$ & $\begin{array}{l}\text { 2-year } \\
\text { OS } \\
(\%)\end{array}$ & Efficacy \\
\hline $\begin{array}{l}\text { Yonemura, } 2006 \\
{[66]}\end{array}$ & 61 & $\mathrm{P} 1$ & $\begin{array}{l}\text { DTX } 40 \mathrm{mg} \\
\text { Carboplatin } 150 \mathrm{mg} \\
2-6 \text { cycles }\end{array}$ & $\begin{array}{l}\text { 5-FU } \\
\text { Methotrexate }\end{array}$ & 14.4 & 67 & & \\
\hline $\begin{array}{l}\text { Yonemura, } 2009 \\
\text { [67] }\end{array}$ & 79 & $\mathrm{P} 1$ & $\begin{array}{l}\text { DTX } 30 \mathrm{mg} / \mathrm{m}^{2} \\
\text { CDDP } 30 \mathrm{mg} / \mathrm{m}^{2} \\
1-5 \text { cycles }\end{array}$ & S-1 & - & & & $\begin{array}{l}\text { Positive cytology changed } \\
\text { to negative in } 63 \%\end{array}$ \\
\hline $\begin{array}{l}\text { Fujiwara, } 2010 \\
\text { [68] }\end{array}$ & 12 & $\begin{array}{l}\text { P1 } \\
\text { Phase I }\end{array}$ & $\begin{array}{l}\text { DTX } 40,50,60 \mathrm{mg} / \mathrm{m}^{2} \\
2 \text { cycles }\end{array}$ & S-1 & - & & & \\
\hline $\begin{array}{l}\text { Fujiwara, } 2012 \\
\text { [69] }\end{array}$ & 18 & $\mathrm{P} 1$ & $\begin{array}{l}\text { DTX } 40,50,60 \mathrm{mg} / \mathrm{m}^{2} \\
2 \text { cycles }\end{array}$ & S-1 & 24.6 & 76 & 54 & \\
\hline Fushida, 2008 [50] & 24 & $\begin{array}{l}\text { P1 } \\
\text { Phase I }\end{array}$ & $\begin{array}{l}\text { DTX } 25,35,45, \\
\quad 60 \mathrm{mg} / \mathrm{m}^{2}\end{array}$ & - & - & & & Response rate: $80 \%$ \\
\hline Fushida, 2013 [70] & 39 & $\begin{array}{l}\mathrm{P} 1 \\
\text { Phase I/II }\end{array}$ & DTX $45 \mathrm{mg} / \mathrm{m}^{2}$ & S-1 & 16.2 & 70.4 & 33.4 & \\
\hline $\begin{array}{l}\text { Kurokawa, } 2015 \\
\text { [71] }\end{array}$ & 5 & $\begin{array}{l}\text { P1/CY1 } \\
\text { Phase I }\end{array}$ & DTX $20,30 \mathrm{mg} / \mathrm{m}^{2}$ & $\begin{array}{l}\mathrm{S}-1 \\
\mathrm{CDDP}\end{array}$ & - & & & 4 underwent $\mathrm{R} 0$ resection \\
\hline Feng, 2015 [72] & 32 & $\begin{array}{l}\text { Stage III/ } \\
\text { IV }\end{array}$ & $\begin{array}{l}\text { DTX } 30,45 \mathrm{mg} / \mathrm{m}^{2} \\
\text { CDDP } 60,75 \mathrm{mg} / \mathrm{m}^{2}\end{array}$ & $\begin{array}{l}5-\mathrm{FU} \\
\text { DTX }\end{array}$ & 9 & & & \\
\hline
\end{tabular}

* $P 1$ denotes macroscopic peritoneal metastasis, and $C Y 1$ positive peritoneal lavage cytology

$I P$ intraperitoneal, $M S T$ median survival time, $O S$ overall survival, DTX docetaxel, $C D D P$ cisplatin

Table 3 Current clinical trials of intraperitoneal chemotherapy with taxane for gastric cancer

\begin{tabular}{|c|c|c|c|c|c|}
\hline Trial & $\mathrm{N}$ & $\begin{array}{l}\text { Objective* } \\
\text { setting }\end{array}$ & IP administration & Systemic therapy & Status \\
\hline PHOENIX-GC [73] & 180 & $\begin{array}{l}\text { P1 } \\
\text { Phase III }\end{array}$ & $\begin{array}{l}\text { PTX } \\
20 \mathrm{mg} / \mathrm{m}^{2}\end{array}$ & $\begin{array}{l}\text { S-1/PTX (+IP) } \\
\text { versus } \\
\text { S-1/CDDP }\end{array}$ & Completed \\
\hline CY-PHOENIX & 38 & $\begin{array}{l}\text { P0CY1 } \\
\text { Phase II }\end{array}$ & $\begin{array}{l}\text { PTX } \\
20 \mathrm{mg} / \mathrm{m}^{2}\end{array}$ & $\begin{array}{l}\text { S-1 } \\
\text { PTX }\end{array}$ & Completion of registration \\
\hline $\begin{array}{l}\text { SOX + IP PTX } \\
(\text { UMIN000012834) }\end{array}$ & 60 & $\begin{array}{l}\text { P1 } \\
\text { Phase II }\end{array}$ & $\begin{array}{l}\text { PTX } \\
40 \mathrm{mg} / \mathrm{m}^{2}\end{array}$ & $\begin{array}{l}\text { S-1 } \\
\text { L-OHP }\end{array}$ & Completed \\
\hline $\begin{array}{l}\text { XP + IP DTX } \\
\text { (UMIN0000116469) }\end{array}$ & 50 & $\begin{array}{l}\text { P1 } \\
\text { Phase II }\end{array}$ & $\begin{array}{l}\text { DTX } \\
10 \mathrm{mg} / \mathrm{m}^{2}\end{array}$ & $\begin{array}{l}\text { Capecitabine } \\
\text { CDDP }\end{array}$ & Completion of registration \\
\hline GAPS study & 50 & SE (P0CY0) & $\begin{array}{l}\text { PTX } \\
20 \mathrm{mg} / \mathrm{m}^{2}\end{array}$ & $\begin{array}{l}\text { S-1 } \\
\text { PTX }\end{array}$ & Completion of registration \\
\hline $\begin{array}{l}\text { FOLFOX + IP PTX } \\
\text { (UMIN000019206) }\end{array}$ & 34 & $\begin{array}{l}\text { P1 (inability of oral ingestion) } \\
\text { Phase I/II }\end{array}$ & $\begin{array}{l}\text { PTX } \\
20 \mathrm{mg} / \mathrm{m}^{2}\end{array}$ & $\begin{array}{l}5-\mathrm{FU} \\
\text { Leucovorin } \\
\text { L-OHP }\end{array}$ & Ongoing \\
\hline
\end{tabular}

* $P 0$ denotes no macroscopic peritoneal metastasis, $P 1$ macroscopic peritoneal metastasis, $C Y O$ negative peritoneal lavage cytology, $C Y 1$ positive peritoneal lavage cytology, and $S E$ serosa-invading gastric cancer

$I P$ intraperitoneal, $P T X$ paclitaxel, $C D D P$ cisplatin, $L-O H P$ oxaliplatin, DTX docetaxel

systemic chemotherapy. The PHOENIX-GC trial was a randomized, multicenter, phase III trial comparing S-1 in combination with intravenous and intraperitoneal PTX to systemic treatment with S-1 plus intravenous CDDP, which is the current standard regimen for advanced/metastatic gastric cancer in Japan. This regimen could have been a 
strong contender for a control group, since it is well documented that the survival advantage afforded by combinations such as S-1/CDDP or S-1/DTX over S-1 alone is greater among gastric cancer patients with nonmeasurable metastatic lesions, such as those with peritoneal disease, than among those with measurable lesions [1, 74]. This study, with a sample size of 180 patients, began accrual in 2011. The final analysis was released at the Annual Meeting of the American Society of Clinical Oncology in 2016, and the details will be published in due time. Intraperitoneal administration of the PTX regimen led to a marginally prolonged OS compared with the standard systemic chemotherapy (MST: 17.7 vs 15.2 months, respectively), but the difference was not significant (stratified log-rank test, $P=0.080$; hazard ratio $0.72,95 \%$ confidence interval $0.49-1.04, \quad P=0.081)$. Although treatment crossover was prohibited, some patients in the control group received intraperitoneal chemotherapy, which marred the final results. Therefore, Ishigami et al. attempted a re-analysis from which those cases were excluded. Their sensitivity analysis, which also took into consideration an ascites-related imbalance between the groups (patients with more severe ascites tended to be allocated to the intraperitoneal administration group), indicated that intraperitoneal PTX was clinically efficacious for gastric cancer with peritoneal metastasis.

The INPACT study was a multi-institutional randomized phase II trial that was conducted to prove the superiority of postoperative intraperitoneal administration of PTX (7 weekly administrations of $60 \mathrm{mg} / \mathrm{m}^{2}$ ) over intravenous administration of PTX (7 weekly administrations of $80 \mathrm{mg} /$ $\mathrm{m}^{2}$ ) in preventing the development of peritoneal carcinomatosis in gastric cancer patients who undergo R0-R2 gastrectomy [75]. This trial aimed to provide a theoretical basis for the implementation of intraperitoneal administration of PTX into various combination chemotherapy regimens in future clinical trials. In a preliminary report, Kodera et al. stated that the repeated intraperitoneal administration of PTX from the day of gastrectomy was safe and feasible and that the incidence of problems associated with the indwelling catheter for intraperitoneal administration was minimal [65]. The results of an analysis of the two-year recurrence-free survival is expected in 2017.

It should be noted that the intraperitoneal administration of anticancer PTX has not been approved and is currently not covered by the national health insurance system in Japan. Outcome data from the randomized clinical trials that would verify the efficacy of intraperitoneal administration of PTX against peritoneal metastasis of gastric cancer are eagerly awaited, and are expected to lead to its approval for official insurance coverage in the future.

DTX is another candidate anticancer drug suitable for intraperitoneal administration. The AUC ratios of the intra- abdominal space to the plasma after intraperitoneal administration of DTX are lower than those for PTX. Fushida et al. argued that intraperitoneal administration of DTX has the pharmacokinetic advantage of exerting dual anticancer effects, via the peritoneal surface and the capillary blood supply [50]. They conducted a phase I/II trial of intraperitoneal administration of DTX plus S-1 and demonstrated a 1-year OS rate of $70 \%$, an MST of 16.2 months, and manageable grade $3 / 4$ toxicities, including anorexia (19\%), neutropenia (7\%), and leukopenia (7\%), which are comparable to the corresponding values obtained in phase II studies of the intraperitoneal administration of PTX [70]. Fujiwara et al. performed two cycles of chemotherapy consisting of the intraperitoneal administration of DTX plus S-1 and subsequent surgery for gastric cancer with positive peritoneal lavage cytology and/ or macroscopic peritoneal dissemination, and demonstrated an MST of 24.6 months [69]. Yonemura et al. explored the intraperitoneal administration of DTX and other anticancer drugs (carboplatin and CDDP) combined with systemic chemotherapy and observed acceptable feasibility and fair outcomes [66, 67].

\section{Discussion}

Peritoneal dissemination is the most frequent pattern of recurrence after surgery with curative intent, and is also a common type of metastasis that accompanies unresectable gastric cancer. Thus, preventing and controlling peritoneal metastasis is a therapeutic principle for achieving prolonged survival of gastric cancer patients. Intraperitoneal administration of anticancer drugs, notably taxanes, combined with conventional systemic chemotherapy has shown encouraging results against peritoneal metastasis of gastric cancer. Intraperitoneal taxanes constitute an ideal regional treatment, as intense intraperitoneal concentrations can be obtained due to the slow clearance of taxanes from the peritoneal cavity, and they are associated with minimal systemic toxicity. Outcomes observed in several clinical trials suggest that repeated intraperitoneal administration of anticancer drugs is a rational approach compared to HIPEC, which is essentially a single intraperitoneal dose of anticancer drugs delivered at an optimal temperature as an adjunct to cytoreductive surgery. HIPEC has been demonstrated to offer a unique antitumor mechanism due to the application of heat and the synergistic antitumor effect of heat and drugs, but whether the elaborate and potentially harmful HIPEC approach is of any added clinical value remains to be proven in a prospective randomized trial, although there appears to be room for the application of this modality, if validated, for selected patients. Given the success achieved 
with intraperitoneal taxanes, HIPEC could be combined with repeated intraperitoneal PTX, while HIPEC itself could be performed repeatedly in a laparoscopic approach, as demonstrated by Yonemura et al. [76]. Intraperitoneal chemotherapy is a less toxic treatment modality than HIPEC, but it is a promising one that could be combined with other modalities to treat peritoneal metastasis of gastric cancer.

There are still some clinical issues to be resolved, even if, as is strongly hoped, the generalization of intraperitoneal chemotherapy is achieved in the future. The first concerns the establishment of second-line and third-line treatments including further intraperitoneal chemotherapy using other available drugs. Several chemotherapeutic procedures consisting of different anticancer drugs administered intravenously and intraperitoneally have proven effective, but prospective clinical trial data focusing on the sequential use of intraperitoneal chemotherapy regimens are lacking. Eradicating peritoneal metastases requires prolonged treatment, and intraperitoneal chemotherapy may still be necessary in the event of treatment failure in the form of the appearance of new lesions through other metastatic pathways. Alteration of the intraperitoneally administered anticancer drugs to circumvent cross-resistance, even among taxanes, may be another option in the case of progressive disease with peritoneal metastasis. The second issue is that it remains to be proven in a prospective trial that gastrectomy is of clinical value after achieving disease control, as exemplified by the disappearance of ascites, peritoneal lavage cytology turning from positive to negative, and the disappearance of macroscopic peritoneal metastasis. Meanwhile, Kitayama et al. demonstrated promising outcomes for gastrectomized patients who had highly advanced gastric cancer, severe peritoneal metastasis, and malignant ascites but showed good response to intraperitoneal chemotherapy using PTX combined with S-1 and intravenous PTX, with an MST of 26.4 months and a 1-year OS of $82 \%$ [77]. These data imply that so-called conversion surgery including gastrectomy with lymphadenectomy after chemotherapy could have a survival benefit for highly selected patients, as long as intraperitoneal chemotherapy shows robust efficacy both before and after surgery. Gastric cancer patients with only a positive peritoneal lavage cytology and without macroscopic peritoneal metastasis may be especially good candidates for conversion surgery when the cytology turns negative with intraperitoneal chemotherapy. Thus, intraperitoneal administration could result in a drastic change to the novel subcategory classification of stage IV GC [78], noting that Yoshida et al. were reluctant to include patients with peritoneal disease in categories in which conversion surgery is the ultimate aim. With intraperitoneal PTX, peritoneal deposits could shrink and disappear just as bulky lymph nodes and liver metastasis could respond to achieve a partial to complete response.

In conclusion, intraperitoneal administration of anticancer drugs against peritoneal metastasis of gastric cancer is safe and feasible. Several phase II trials and a phase III trial have recently demonstrated the efficacy of repeated intraperitoneal chemotherapy, mainly with taxanes, combined with systemic chemotherapy. The generalization of intraperitoneal chemotherapy under the official approval of the government is hoped for in Japan. There will be room for improvement and controversy regarding the selection of the appropriate regimen of intraperitoneal chemotherapy, sequential treatment after the failure of the initial therapy, and conversion surgery after achieving control of peritoneal metastasis.

\section{Compliance with ethical standards}

Human rights statement All procedures followed were in accordance with the ethical standards of the responsible committee on human experimentation (institutional and national) and with the Helsinki Declaration of 1964 and later versions.

Funding This research did not receive any specific grant from funding agencies in the public, commercial, or not-for-profit sectors.

Conflict of interest The authors declare that they have no conflict of interest.

\section{References}

1. Koizumi W, Narahara H, Hara T, Takagane A, Akiya T, Takagi $\mathrm{M}$, et al. S-1 plus cisplatin versus S-1 alone for first-line treatment of advanced gastric cancer (SPIRITS trial): a phase III trial. Lancet Oncol. 2008;9:215-21.

2. Bang YJ, Van Cutsem E, Feyereislova A, Chung HC, Shen L, et al. ToGA trial investigators. Trastuzumab in combination with chemotherapy versus chemotherapy alone for treatment of HER2positive advanced gastric or gastro-oesophageal junction cancer (ToGA): a phase 3, open-label, randomized controlled trial. Lancet. 2010;376:687-97.

3. Wilke H, Muro K, Van Cutsem E, Oh SC, Bodoky G, Shimada Y, et al. RAINBOW Study Group. Ramucirumab plus paclitaxel versus placebo plus paclitaxel in patients with previously treated advanced gastric or gastro-oesophageal junction adenocarcinoma (RAINBOW): a double-blind, randomised phase 3 trial. Lancet Oncol. 2014;15:1224-35.

4. Fuchs CS, Tomasek J, Yong CJ, Dumitru F, Passalacqua R, Goswami $\mathrm{C}$, et al. REGARD trial investigators. Ramucirumab monotherapy for previously treated advanced gastric or gastrooesophageal junction adenocarcinoma (REGARD): an international, randomised, multicentre, placebo-controlled, phase 3 trial. Lancet. 2014;383:31-9.

5. Nishina T, Boku N, Gotoh M, Shimada Y, Hamamoto Y, Yasui $\mathrm{H}$, et al. Gastrointestinal Oncology Study Group of the Japan Clinical Oncology Group. Randomized phase II study of secondline chemotherapy with the best available 5-fluorouracil regimen versus weekly administration of paclitaxel in far advanced gastric cancer with severe peritoneal metastases refractory to 5-fluorouracil-containing regimens (JCOG0407). Gastric Cancer. 2016;19:902-10. 
6. Imamoto H, Oba K, Sakamoto J, Iishi H, Narahara H, Yumiba T, et al. Assessing clinical benefit response in the treatment of gastric malignant ascites with non-measurable lesions: a multicenter phase II trial of paclitaxel for malignant ascites secondary to advanced/recurrent gastric cancer. Gastric Cancer. 2011;14:81-90.

7. Jacquet P, Sugarbaker PH. Peritoneal-plasma barrier. Cancer Treat Res. 1996;82:53-63.

8. Dedrick RL, Myers CE, Bungay PM, DeVita VT Jr. Pharmacokinetic rationale for peritoneal drug administration in the treatment of ovarian cancer. Cancer Treat Rep. 1978;62:1-11.

9. Sugarbaker PH, Van der Speeten K. Surgical technology and pharmacology of hyperthermic perioperative chemotherapy. J Gastrointest Oncol. 2016;7:29-44.

10. Markman M, Walker JL. Intraperitoneal chemotherapy of ovarian cancer: a review, with a focus on practical aspects of treatment. J Clin Oncol. 2006;24:988-94.

11. Piso P, Arnold D. Multimodal treatment approaches for peritoneal carcinosis in colorectal cancer. Dtsch Arztebl Int. 2011;108:802-8.

12. Chua TC, Moran BJ, Sugarbaker PH, Levine EA, Glehen O, Gilly FN, et al. Early-and long-term outcome data of patients with pseudomyxoma peritonei from appendiceal origin treated by a strategy of cytoreductive surgery and hyperthermic intraperitoneal chemotherapy. J Clin Oncol. 2012;30:2449-56.

13. Chua TC, Chong $\mathrm{CH}$, Morris DL. Peritoneal mesothelioma: current status and future directions. Surg Oncol Clin N Am. 2012;21:635-43.

14. Glehen O, Gilly FN, Arvieux C, Cotte E, Boutitie F, Mansvelt B, et al. Association Française de Chirurgie. Peritoneal carcinomatosis from gastric cancer: a multi-institutional study of 159 patients treated by cytoreductive surgery combined with perioperative intraperitoneal chemotherapy. Ann Surg Oncol. 2010;17:2370-7.

15. Rudloff U, Langan RC, Mullinax JE, Beane JD, Steinberg SM, Beresnev $\mathrm{T}$, et al. Impact of maximal cytoreductive surgery plus regional heated intraperitoneal chemotherapy (HIPEC) on outcome of patients with peritoneal carcinomatosis of gastric origin: results of the GYMSSA trial. J Surg Oncol. 2014;110:275-84.

16. Glehen O, Schreiber V, Cotte E, Sayag-Beaujard AC, Osinsky D, Freyer G, et al. Cytoreductive surgery and intraperitoneal chemohyperthermia for peritoneal carcinomatosis arising from gastric cancer. Arch Surg. 2004;139:20-6.

17. Gill RS, Al-Adra DP, Nagendran J, Campbell S, Shi X, Haase E, et al. Treatment of gastric cancer with peritoneal carcinomatosis by cytoreductive surgery and HIPEC: a systematic review of survival, mortality, and morbidity. J Surg Oncol. 2011;104:692-8.

18. Yang XJ, Huang CQ, Suo T, Mei LJ, Yang GL, Cheng FL, et al. Cytoreductive surgery and hyperthermic intraperitoneal chemotherapy improves survival of patients with peritoneal carcinomatosis from gastric cancer: final results of a phase III randomized clinical trial. Ann Surg Oncol. 2011;18:1575-81.

19. Yonemura Y, Kawamura T, Bandou E, Takahashi S, Sawa T, Matsuki N. Treatment of peritoneal dissemination from gastric cancer by peritonectomy and chemohyperthermic peritoneal perfusion. Br J Surg. 2005;92:370-5.

20. Fujimoto S, Shrestha RD, Kokubun M, Ohta M, Takahashi M, Kobayashi $\mathrm{K}$, et al. Intraperitoneal hyperthermic perfusion combined with surgery effective for gastric cancer patients with peritoneal seeding. Ann Surg. 1988;208:36-41.

21. Kunisaki C, Shimada H, Akiyama H, Nomura M, Matsuda G, Otsuka Y, et al. Therapeutic outcomes of continuous hyperthermic peritoneal perfusion against advanced gastric cancer with peritoneal carcinomatosis. Hepatogastroenterology. 2006;53: 473-8.
22. Armstrong DK, Bundy B, Wenzel L, Huang HQ, Baergen R, Lele $\mathrm{S}$, et al. Gynecologic Oncology Group. Intraperitoneal cisplatin and paclitaxel in ovarian cancer. N Engl J Med. 2006;354:34-43.

23. Morgan RJ Jr, Alvarez RD, Armstrong DK, Boston B, Burger RA, Chen LM, et al. National Comprehensive Cancer Network. Epithelial ovarian cancer. J Natl Compr Canc Netw. 2011;9:82-113.

24. Emoto S, Ishigami H, Hidemura A, Yamaguchi H, Yamashita H, Kitayama $J$, et al. Complications and management of an implanted intraperitoneal access port system for intraperitoneal chemotherapy for gastric cancer with peritoneal metastasis. Jpn J Clin Oncol. 2012;42:1013-9.

25. Walker JL, Armstrong DK, Huang HQ, Fowler J, Webster, et al. Intraperitoneal catheter outcomes in a phase III trial of intravenous versus intraperitoneal chemotherapy in optimal stage III ovarian and primary peritoneal cancer: a Gynecologic Oncology Group Study. Gynecol Oncol. 2006;100:27-32.

26. Kamei T, Kitayama J, Yamaguchi H, Soma D, Emoto S, Konno $\mathrm{T}$, et al. Spatial distribution of intraperitoneally administrated paclitaxel nanoparticles solubilized with poly(2-methacryloxyethyl phosphorylcholine-co- $n$-butyl methacrylate) in peritoneal metastatic nodules. Cancer Sci. 2011;102:200-5.

27. González-Moreno S, González-Bayón LA, Ortega-Pérez G. Hyperthermic intraperitoneal chemotherapy: rationale and technique. World J Gastrointest Oncol. 2010;2:68-75.

28. Spratt JS, Adcock RA, Muskovin M, Sherrill W, McKeown J. Clinical delivery system for intraperitoneal hyperthermic chemotherapy. Cancer Res. 1980;40:256-60.

29. Hagiwara A, Takahashi T, Kojima O, Sawai K, Yamaguchi T, Yamane T, et al. Prophylaxis with carbon-adsorbed mitomycin against peritoneal recurrence of gastric cancer. Lancet. 1992;339:629-31.

30. Yu W, Whang I, Chung HY, Averbach A, Sugarbaker PH. Indications for early postoperative intraperitoneal chemotherapy of advanced gastric cancer: results of a prospective randomized trial. World J Surg. 2001;25:985-90.

31. Yano M, Yasuda T, Fujiwara Y, Takiguchi S, Miyata H, Monden M. Preoperative intraperitoneal chemotherapy for patients with serosa-infiltrating gastric cancer. J Surg Oncol. 2004;88:39-43.

32. Newman E, Potmesil M, Ryan T, Marcus S, Hiotis S, Yee H, et al. Neoadjuvant chemotherapy, surgery, and adjuvant intraperitoneal chemotherapy in patients with locally advanced gastric or gastroesophageal junction carcinoma: a phase II study. Semin Oncol. 2005;32:S97-100.

33. Shi C, Yang B, Chen Q, Yang J, Fan N. Retrospective analysis of adjuvant intraperitoneal chemotherapy effect prognosis of resectable gastric cancer. Oncology. 2011;80:289-95.

34. Fujiwara Y, Takiguchi S, Nakajima K, Miyata H, Yamasaki M, Kurokawa Y, et al. Neoadjuvant intraperitoneal and systemic chemotherapy for gastric cancer patients with peritoneal dissemination. Ann Surg Oncol. 2011;18:3726-31.

35. Xue SL, Su HF, Hu XQ, Deng X, Hu ML, Xie CY. Adjuvant combined systemic chemotherapy and intraperitoneal chemotherapy for locally advanced gastric cancer. Oncol Lett. 2012;4:1309-14.

36. Kwon OK, Chung HY, Yu W. Early postoperative intraperitoneal chemotherapy for macroscopically serosa-invading gastric cancer patients. Cancer Res Treat. 2014;46:270-9.

37. Sautner T, Hofbauer F, Depisch D, Schiessel R, Jakesz R. Adjuvant intraperitoneal cisplatin chemotherapy does not improve long-term survival after surgery for advanced gastric cancer. J Clin Oncol. 1994;12:970-4.

38. Miyashiro I, Furukawa H, Sasako M, Yamamoto S, Nashimoto A, Nakajima T, et al. Gastric Cancer Surgical Study Group in the Japan Clinical Oncology Group. Randomized clinical trial of adjuvant chemotherapy with intraperitoneal and intravenous 
cisplatin followed by oral fluorouracil (UFT) in serosa-positive gastric cancer versus curative resection alone: final results of the Japan Clinical Oncology Group trial JCOG9206-2. Gastric Cancer. 2011;14:212-8.

39. Cheong JH, Shen JY, Song CS, Hyung WJ, Shen JG, Choi SH, et al. Early postoperative intraperitoneal chemotherapy following cytoreductive surgery in patients with very advanced gastric cancer. Ann Surg Oncol. 2007;14:61-8.

40. Kuramoto M, Shimada S, Ikeshima S, Matsuo A, Yagi Y, Matsuda $\mathrm{M}$, et al. Extensive intraoperative peritoneal lavage as a standard prophylactic strategy for peritoneal recurrence in patients with gastric carcinoma. Ann Surg. 2009;250:242-6.

41. Markman M. Intraperitoneal antineoplastic drug delivery: rationale and results. Lancet Oncol. 2003;4:277-83.

42. Ceelen WP, Flessner MF. Intraperitoneal therapy for peritoneal tumors: biophysics and clinical evidence. Nat Rev Clin Oncol. 2010;7:108-15.

43. Yan TD, Cao CQ, Munkholm-Larsen S. A pharmacological review on intraperitoneal hemotherapy for peritoneal malignancy. World J Gastrointest Oncol. 2010;2:109-16.

44. Yonemura Y, Elnemr A, Endou Y, Hirano M, Mizumoto A, Takao N, et al. Multidisciplinary therapy for treatment of patients with peritoneal carcinomatosis from gastric cancer. World $\mathbf{J}$ Gastrointest Oncol. 2010;2:85-97.

45. Yamaguchi K, Tada M, Horikoshi N, Otani T, Takiuchi H, Saitoh S, et al. Paclitaxel Gastric Cancer Study Group in Japan. Phase II study of paclitaxel with 3-h infusion in patients with advanced gastric cancer. Gastric Cancer. 2002;5:90-5.

46. Ajani JA, Fairweather J, Dumas P, Patt YZ, Pazdur R, Mansfield PF. Phase II study of taxol in patients with advanced gastric carcinoma. Cancer J Sci Am. 1998;4:269-74.

47. Einzig AI, Neuberg D, Remick SC, Karp DD, O’Dwyer PJ, Stewart JA, et al. Phase II trial of docetaxel (Taxotere) in patients with adenocarcinoma of the upper gastrointestinal tract previously untreated with cytotoxic chemotherapy: the Eastern Cooperative Oncology Group (ECOG) results of protocol E1293. Med Oncol. 1996;13:87-93.

48. Flessner MF, Fenstermacher JD, Blasberg RG, Dedrick RL. Peritoneal absorption of macromolecules studied by quantitative autoradiography. Am J Physiol. 1985;248:H26-32.

49. Wang ZB, Li M, Li JC. Recent advances in the research of lymphatic stomata. Anat Rec (Hoboken). 2010;293(5): 754-61.

50. Fushida S, Kinoshita J, Yagi Y, Funaki H, Kinami S, Ninomiya I, et al. Dual anti-cancer effects of weekly intraperitoneal docetaxel in treatment of advanced gastric cancer patients with peritoneal carcinomatosis: a feasibility and pharmacokinetic study. Oncol Rep. 2008;19:1305-10.

51. Imano M, Peng YF, Itoh T, Nishikawa M, Satou T, Yasuda A, et al. A preliminary study of single intraperitoneal administration of paclitaxel followed by sequential systemic chemotherapy with S-1 plus paclitaxel for advanced gastric cancer with peritoneal metastasis. Anticancer Res. 2012;32:4071-5.

52. Kodera Y, Ito Y, Ito S, Ohashi N, Mochizuki Y, Yamamura Y, et al. Intraperitoneal paclitaxel: a possible impact of regional delivery for prevention of peritoneal carcinomatosis in patients with gastric carcinoma. Hepatogastroenterology. 2007;54: 960-3.

53. Ishigami H, Kitayama J, Otani K, Kamei T, Soma D, Miyato H, et al. Phase I pharmacokinetic study of weekly intravenous and intraperitoneal paclitaxel combined with S-1 for advanced gastric cancer. Oncology. 2009;76:311-4.

54. Yonemura Y, Endou Y, Bando E, Kuno K, Kawamura T, Kimura $\mathrm{M}$, et al. Effect of intraperitoneal administration of docetaxel on peritoneal dissemination of gastric cancer. Cancer Lett. 2004; 210:189-96.
55. Soma D, Kitayama J, Ishigami H, Kaisaki S, Nagawa H. Different tissue distribution of paclitaxel with intravenous and intraperitoneal administration. J Surg Res. 2009;155:142-6.

56. Yamaguchi H, Kitayama J, Ishigami H, Kazama S, Nozawa H, Kawai $\mathrm{K}$, et al. Breakthrough therapy for peritoneal carcinomatosis of gastric cancer: intraperitoneal chemotherapy with taxanes. World J Gastrointest Oncol. 2015;7:285-91.

57. Kitayama J, Ishigami $\mathrm{H}$, Yamaguchi $\mathrm{H}$, Emoto $\mathrm{S}$, Watanabe $\mathrm{T}$. Intraperitoneal aclitaxel is useful as adjuvant chemotherapy for advanced gastric cancer with serosal exposure. Case Rep Oncol. 2014;24(7):58-64.

58. Peng YF, Imano M, Itoh T, Satoh T, Chiba Y, Imamoto H, et al. A phase II trial of perioperative chemotherapy involving a single intraperitoneal administration of paclitaxel followed by sequential S-1 plus intravenous paclitaxel for serosa-positive gastric cancer. J Surg Oncol. 2015;111:1041-6.

59. Imano M, Imamoto $H$, Itoh $T$, Satou $T$, Peng YF, Yasuda A, et al. Impact of intraperitoneal chemotherapy after gastrectomy with positive cytological findings in peritoneal washings. Eur Surg Res. 2011;47:254-9.

60. Imano M, Yasuda A, Itoh T, Satou T, Peng YF, Kato H, et al. Phase II study of single intraperitoneal chemotherapy followed by systemic chemotherapy for gastric cancer with peritoneal metastasis. J Gastrointest Surg. 2012;16:2190-6.

61. Imano M, Imamoto H, Itoh T, Satou T, Peng YF, Yasuda A, et al. Safety of intraperitoneal administration of paclitaxel after gastrectomy with en-bloc D2 lymph node dissection. J Surg Oncol. 2012;105:43-7.

62. Ishigami H, Kitayama J, Kaisaki S, Hidemura A, Kato M, Otani $\mathrm{K}$, et al. Phase II study of weekly intravenous and intraperitoneal paclitaxel combined with S-1 for advanced gastric cancer with peritoneal metastasis. Ann Oncol. 2010;21:67-70.

63. Kurita N, Shimada M, Iwata T, Nishioka M, Morimoto S, Yoshikawa $\mathrm{K}$, et al. Intraperitoneal infusion of paclitaxel with S-1 for peritoneal metastasis of advanced gastric cancer: phase I study. J Med Invest. 2011;58:134-9.

64. Yamaguchi H, Kitayama J, Ishigami H, Emoto S, Yamashita $\mathrm{H}$, Watanabe T. A phase 2 trial of intravenous and intraperitoneal paclitaxel combined with S-1 for treatment of gastric cancer with macroscopic peritoneal metastasis. Cancer. 2013;119:3354-8.

65. Kodera Y, Takahashi N, Yoshikawa T, Takiguchi N, Fujitani K, Ito Y, et al (2016) Feasibility of weekly intraperitoneal versus intravenous paclitaxel therapy delivered from the day of radical surgery for gastric cancer: a preliminary safety analysis of the INPACT study, a randomized controlled trial. Gastric Cancer. (Epub ahead of print) PubMed PMID: 26879545.

66. Yonemura Y, Bandou E, Sawa T, Yoshimitsu Y, Endou Y, Sasaki $\mathrm{T}$, et al. Neoadjuvant treatment of gastric cancer with peritoneal dissemination. Eur J Surg Oncol. 2006;32:661-5.

67. Yonemura Y, Endou Y, Shinbo M, Sasaki T, Hirano M, Mizumoto A, et al. Safety and efficacy of bidirectional chemotherapy for treatment of patients with peritoneal dissemination from gastric cancer: selection for cytoreductive surgery. J Surg Oncol. 2009;100:311-6.

68. Fujiwara Y, Nishida T, Takiguchi S, Nakajima K, Miyata H, Yamasaki $\mathrm{M}$, et al. Feasibility study of $\mathrm{S}-1$ and intraperitoneal docetaxel combination chemotherapy for gastric cancer with peritoneal dissemination. Anticancer Res. 2010;30:1335-9.

69. Fujiwara Y, Takiguchi S, Nakajima K, Miyata H, Yamasaki M, Kurokawa Y, et al. Intraperitoneal docetaxel combined with S-1 for advanced gastric cancer with peritoneal dissemination. J Surg Oncol. 2012;105:38-42.

70. Fushida S, Kinoshita J, Kaji M, Hirono Y, Goda F, Yagi Y, et al. Society for Study of Peritoneal Carcinomatosis in Gastric Cancer. Phase I/II study of intraperitoneal docetaxel plus S-1 for the 
gastric cancer patients with peritoneal carcinomatosis. Cancer Chemother Pharmacol. 2013;71:1265-72.

71. Kurokawa Y, Hamakawa T, Miyazaki Y, Takahashi T, Yamasaki $\mathrm{M}$, Miyata $\mathrm{H}$, et al. Preoperative systemic and intraperitoneal chemotherapy consisting of S-1, cisplatin and docetaxel in patients with marginally resectable gastric cancer. Anticancer Res. 2015;35:2223-8.

72. Feng ZL, Chen LB, Liu ZY, Chen XJ, Ren XC, Liu YE, et al. DCF intraperitoneal and intravenous dual chemotherapy regimen for advanced gastric cancer: a feasibility study. Oncol Lett. 2015;9:491-7.

73. Ishigami H, Fujiwara Y, Fukushima R, Nashimoto A, Yabusaki $\mathrm{H}$, Imamoto $\mathrm{H}$, et al. Phase III study of intraperitoneal paclitaxel plus S-1/paclitaxel compared with S-1/cisplatin in gastric cancer patients with peritoneal metastasis: PHOENIX-GC trial. J Clin Oncol. 2016;34(suppl):abstr 4014.

74. Koizumi W, Kim YH, Fujii M, Kim HK, Imamura H, Lee KH, et al. JACCRO and KCSG Study Group. Addition of docetaxel to S-1 without platinum prolongs survival of patients with advanced gastric cancer: a randomized study (START). J Cancer Res Clin Oncol. 2014;140:319-28.
75. Kodera Y, Imano M, Yoshikawa T, Takahashi N, Tsuburaya A, Miyashita Y, et al. A randomized phase II trial to test the efficacy of intra-peritoneal paclitaxel for gastric cancer with high risk for the peritoneal metastasis (INPACT trial). Jpn J Clin Oncol. 2011;41:283-6.

76. Yonemura Y, Ishibashi H, Hirano M, Mizumoto A, Takeshita K, Noguchi K, et al (2016) Effects of neoadjuvant laparoscopic hyperthermic intraperitoneal chemotherapy and neoadjuvant intraperitoneal/systemic chemotherapy on peritoneal metastases from gastric cancer. Ann Surg Oncol. (Epub ahead of print) PubMed PMID: 27506661.

77. Kitayama J, Ishigami H, Yamaguchi H, Yamashita H, Emoto S, Kaisaki S, et al. Salvage gastrectomy after intravenous and intraperitoneal paclitaxel (PTX) administration with oral S-1 for peritoneal dissemination of advanced gastric cancer with malignant ascites. Ann Surg Oncol. 2014;21:539-46.

78. Yoshida K, Yamaguchi K, Okumura N, Tanahashi T, Kodera Y. Is conversion therapy possible in stage IV gastric cancer: the proposal of new biological categories of classification. Gastric Cancer. 2016;19:329-38. 